\title{
O ENSINO SUPERIOR NO OCTÊNIO FHC
}

\author{
Luiz ANTÔNIO CunHA*
}

RESUMO: Este artigo se propõe a analisar o ensino superior brasileiro durante o período $1995 / 2002$, para o que são focalizadas, principalmente, as políticas do governo federal. Depois de apresentar as mudanças determinadas pela Lei de Diretrizes e Bases da Educação Nacional (1996), o artigo relaciona e analisa as medidas do Governo Fernando Henrique Cardoso que constituíram uma verdadeira normatização fragmentada do ensino superior, a saber: o acesso aos cursos de graduação, o poder docente na gestão universitária, o Conselho Nacional de Educação, a avaliação e o formato institucional. $\mathrm{O}$ artigo finaliza com um balanço dos oito anos do Governo Fernando Henrique Cardoso no campo do ensino superior, o qual revela uma intensificação da privatização no período, assim como um deslocamento da fronteira entre o setor público e o setor privado.

Palavras-chave: Ensino superior. Universidade. Privatização. Educação brasileira.

\section{HighER EDUCATION UNDER THE CARDOSO ADMINISTRATION}

(1995-2002)

ABSTRACT: This paper analyzes the Brazilian higher education in the 1995-2002 period focusing mainly on the Federal Government's policies. After presenting the changes determined in the Lei de Diretrizes e Bases da Educação Nacional (Brazilian Education Basic Tenets Law), in 1996, it lists and analyzes the measures taken during the Cardoso administration. They constituted a truly fragmented normalization of higher education and affected the access to undergraduate courses, the power of teachers in the university administration, the Conselho Nacional de Educação (Brazilian Education Council), assessment and the very institutional format. Finally, a balance of these

Professor titular de Educação Brasileira, Faculdade de Educação da Universidade Federal do Rio de Janeiro (UfRJ).E-mail: lacunha@iis.com.br

Educ. Soc., Campinas, vol. 24, n. 82, p. 37-61, abril 2003 
eight years reveals both the intensification of privatization and a shift of the border between public and private sector.

Key words: Higher education. University. Privatization. Brazilian Education.

riste desfecho teve o primeiro governo civil eleito diretamente no Brasil, em 1989, depois de duas décadas de ditadura militar e uma problemática transição para a democracia. Com efeito, o presidente Fernando Collor de Melo (primeiro civil eleito diretamente depois de 20 anos de ditadura militar) foi destituído de seu cargo e teve os direitos políticos cassados por decisão do Congresso Nacional, apoiado por inédita manifestação popular em todo o país.

$\mathrm{O}$ apoio popular granjeado pela política de estabilização financeira do vice, então presidente Itamar Franco - o Plano Real -, incentivou seu ministro da fazenda, Fernando Henrique Cardoso, a candidatar-se à Presidência da República, por uma frente partidária de centro-direita. Em 1998, impulsionado pelo sucesso do Plano Real, FHC reeditou a mesma frente política como base de apoio de sua candidatura à reeleição, sem oposição consistente nem eficaz, o que só veio a acontecer em 2002, quando uma frente de centro-esquerda elegeu Luiz Inácio "Lula" da Silva presidente da República. Assim, FHC ocupou a Presidência da República durante oito anos, o único até então que o fez, eleito que foi por dois mandatos seguidos.

Este texto se propõe a analisar o ensino superior durante o período $1995 / 2002$, para o que serão focalizadas, principalmente, as políticas do governo federal. Serão deixadas de lado, portanto, as políticas dos governos estaduais que, no regime federativo brasileiro, têm amplas margens de atuação distinta e até contrárias àquele.

A proposta de governo do candidato FHC para seu primeiro mandato (Cardoso, 1994) foi elaborada por uma equipe coordenada pelo economista Paulo Renato Souza, ex-secretário da Educação do Estado de São Paulo, ex-reitor da Universidade Estadual de Campinas, naquele momento, técnico do Banco Interamericano de Desenvolvimento (BID). Vitorioso o candidato e empossado FHC na Presidência da República, Paulo Renato Souza foi nomeado ministro da Educação, cargo que ocupou de 1995 a 2002, vale dizer, durante os dois mandatos do presidente.

A característica mais marcante da educação como meta prioritária da proposta é o destaque para o papel econômico da educação, como 
"base do novo estilo de desenvolvimento", cujo dinamismo e sustentação provêm de fora dela mesma - do progresso científico e tecnológico. Essa indução atuaria no sistema educacional pelo topo, isto é, pela universidade, entendendo-se que a competência científica e tecnológica é fundamental para garantir a qualidade do ensino básico, secundário e técnico, assim como aumentar a qualificação geral da população. Para se conseguir isso, a proposta afirmava a necessidade de se estabelecer uma "verdadeira parceria" entre setor privado e governo, entre universidade e indústria, tanto na gestão quanto no financiamento do sistema brasileiro de desenvolvimento científico e tecnológico. ${ }^{1}$

A proposta referia-se negativamente à rede federal de ensino superior, que "precisaria ser revista", silenciando-se quanto ao conjunto do ensino privado, que é majoritário e, inegavelmente, de qualidade bem inferior. Assim, dizia ser inaceitável que a rede federal consumisse de $70 \%$ a $80 \%$ do orçamento do Ministério da Educação (uma estimativa, aliás, bastante exagerada) para atender apenas a $22 \%$ dos estudantes de graduação.

A política para o ensino superior deveria promover uma "revolução administrativa": o objetivo seria a administração mais racional dos recursos e a utilização da capacidade ociosa, visando a generalizar os cursos noturnos e aumentar as matrículas, sem despesas adicionais. Para isso, as universidades deveriam ter uma "efetiva autonomia", mas que condicionasse o montante de verbas que viessem a receber à avaliação de desempenho. Nessa avaliação, seriam levados em conta, especialmente, o número de estudantes efetivamente formados, as pesquisas realizadas e os serviços prestados. A racionalização dos gastos e o aumento da produtividade deveriam se refletir em aumentos salariais de professores e de funcionários.

A primeira e mais importante opção da nova equipe dirigente do MEC foi no tocante à Lei de Diretrizes e Bases da Educação Nacional. ${ }^{2}$ Diante dos dois projetos, optou por apoiar o do Senado, já que o texto de Darcy Ribeiro, além de menos minucioso, tinha em seu autor maior receptividade para modificar a versão original a fim de adequar-se às políticas governamentais, como já havia demonstrado no Governo Collor. Mas, ao invés de buscar incluir dispositivos específicos, o MEC preferiu que o projeto deixasse de tratar dos temas que seriam objeto de projetos de lei específicos, ou o fizesse de modo bastante genérico, permitindo articulações com as medidas que se tomavam. Assim, enquanto o projeto de LDB do Senado prosseguia na tramitação parlamentar, pelas comissões e pelo plenário, ele foi sendo adaptado, 
com admirável plasticidade, às políticas que o Poder Executivo elaborava. No que dizia respeito ao ensino superior (mas não só a ele), o ministério elaborou projetos de lei, encaminhados pelo presidente da República ao Congresso, mediante projetos de reforma constitucional, projetos de lei e decretos que serão comentados mais adiante.

$\mathrm{Na}$ reconstrução da lógica intrínseca ao processo de reforma do ensino superior em curso no Brasil, os elementos apresentados revelam que há um modelo concebido em meados da década de 1980, cuja versão paradigmática foi expressa pelo Grupo Executivo para a Reformulação da Educação Superior (GERES). A continuidade das propostas apresentadas recorrentemente, desde então, deve ser entendida como produto, também, da permanência no governo de dirigentes e quadros técnicos, o que permite traçar um elemento de continuidade entre os governos José Sarney, Fernando Collor, Itamar Franco e Fernando Henrique Cardoso, pelo menos no que se refere ao Ministério da Educação.

$\mathrm{Na}$ montagem de suas políticas para o ensino superior - mas não só para essas -, o MEC traçou uma estratégia de enfrentamento parcial de problemas e de adversários. Uma estratégia semelhante à do governo como um todo no que se refere às reformas constitucionais. No caso da área educacional, ela foi ainda mais elaborada, já que os níveis mais baixos da legislação atropelaram os mais altos. Assim, em vem de investir, primeiramente, na reforma dos dispositivos da Constituição que diziam respeito à educação; depois, num projeto de LDB articulado com a nova redação da Carta Magna; em vez de investir numa lei geral para o ensino superior, o MEC foi traçando, no varejo, as diretrizes e bases da educação nacional, não contra o que seria a lei maior de educação, mas por fora dela.

Assim, a LDB minimalista, finalmente aprovada, não contém, propriamente, todas as diretrizes nem todas as bases da educação nacional. Elas terão de ser procuradas dentro, mas, também, fora dela. Com efeito, a LDB diz pouco ou quase nada sobre questôes tão importantes quanto o Conselho Nacional de Educação (composição, atribuições etc.) ou a avaliação universitária.

\section{LDB: determinação e omissão}

Para compreender a amplitude e o conteúdo da normatização do ensino superior pela LDB, cumpre observar o que essa lei determina tanto quanto suas omissóes. Vejamos, antes de tudo, o primeiro tipo de referências. 
O poder do Estado no âmbito do ensino superior foi reassegurado em novas bases, mediante a dupla reconhecimento/credenciamento e avaliação. A autorização e o reconhecimento de cursos, bem como o reconhecimento de instituiçôes de ensino superior, ${ }^{3}$ passaram a ter prazos limitados, sendo renovados periodicamente, após processo regular de avaliaçãa. Caso existissem deficiências, a lei previa que, no caso em que a avaliação fosse negativa, o curso ou a instituição receberiam um "prazo de saneamento", após o que nova avaliação mostraria a reabilitação do curso ou da instituição, caso contrário haveria intervenção na instituição, suspensão temporária da autonomia (se se tratasse de universidade) ou, ainda, o descredenciamento.

A instituição universitária foi definida, de modo genérico, como a que desenvolve "produção intelectual institucionalizada mediante o estudo sistemático dos temas e problemas mais relevantes, tanto do ponto de vista científico e cultural quanto regional e nacional". Mas ela deveria cumprir requisitos bem específicos, relativos à qualificação e dedicação dos docentes: um terço deles deveria ter títulos de pósgraduação de mestre ou de doutor; um terço (não necessariamente os mesmos) deveria atuar na instituição em tempo integral.

Ao contrário da característica necessária às universidades brasileiras, desde a primeira, criada em 1920, a universalidade de campo foi abolida pela $L D B$, que facultou a existência de universidades especializadas por campo do saber. Além disso, outro elemento até então exclusivo da universidade foi alterado: a autonomia, a qual a LDB permitiu que fosse estendida a instituiçōes que comprovassem alta qualificação para o ensino ou a pesquisa, constatada em avaliação pelo Poder Público. ${ }^{4}$

Diferentemente da primeira LDB (de 1961), a de 1996 tratou detalhadamente da autonomia universitária, estabelecendo, em dois artigos, contendo cada um numerosos itens, o que esse tipo de instituição poderia fazer. Dentre eles, reassegurou a possibilidade (negada às instituiçôes isoladas de ensino superior) de criar e extinguir cursos, assim como de determinar o número de vagas de cada um, elementos importantes para a sintonia das instituiçóes privadas com o mercado.

As universidades públicas estariam sujeitas a um regime jurídico especial, o qual, ao contrário das demais autarquias, permitir-lhes-ia grande flexibilidade na organização do quadro de pessoal docente e administrativo, tanto quanto no emprego de recursos financeiros. Mas, como esse regime jurídico não foi definido, as universidades públicas, especialmente as federais, permaneceram submetidas a uma pletora de regulamentos que cerceiam sobremaneira suas administraçōes. ${ }^{5}$ 
O disposto em decreto presidencial de 1995, relativo à composição dos órgãos colegiados das instituições federais de ensino superior, foi estendido pela LDB a todas as congêneres estaduais e municipais, universitárias e não. Dizia a lei que elas devem obedecer ao princípio da gestão democrática, que consiste na existência de órgãos colegiados deliberativos, dos quais devem participar os segmentos da comunidade institucional (docentes, funcionários técnico-administrativos e estudantes), local e regional. Qualquer que seja o órgão colegiado e qualquer que seja sua atribuição, os docentes devem ocupar $70 \%$ dos lugares. Essa composição foi destacada para os órgãos colegiados que têm a atribuição de elaborar e modificar estatutos e regimentos, assim como escolher diretores das unidades e reitores das universidades.

Além dos cursos de graduação, pós-graduação e extensão, que as instituiçōes de ensino superior brasileiras vinham oferecendo, a LDB introduziu um tipo novo, o dos cursos seqüenciais, por campo de saber. Como a lei não os definiu, o Conselho Nacional de Educação viu-se com a ingrata tarefa de dar conteúdo a uma expressão desconhecida. ${ }^{6}$

De acordo com a normatização do CNE, os cursos seqüenciais podem ser de dois tipos, mas sempre destinados a concluintes do ensino médio. $\mathrm{O}$ primeiro tipo é curso seqüencial de complementação de estudos. São cursos não sujeitos a autorização nem reconhecimento pelo MEC, embora devam estar ligados academicamente a cursos de graduação reconhecidos. Os do segundo tipo, os cursos seqüenciais de formação específica, estão sujeitos ao MEC e ligados a cursos de graduação, tendo, portanto, carga horária e duração mínimas.

Em sua concepção original, os cursos seqüenciais por campo de saber deveriam ser uma alternativa à rigidez dos cursos de graduação, em especial quando eles estavam submetidos a currículos mínimos, que, segundo se criticava, eram muito exigentes, além de não permitirem a indispensável flexibilidade diante das mudanças no mundo do trabalho. Assim, os estudantes poderiam definir trajetórias individuais ou coletivas que, sem buscarem graus acadêmicos, permitissem complementar estudos realizados no ensino médio, ou, então, obter formação específica em tempo mais curto e com maior especificidade do que os cursos de graduação exigiriam.

Mas o que aconteceu foi distinto do projetado pelo senador Darcy Ribeiro, o patrono da LDB-96. Com efeito, foram as instituiçōes privadas de mais baixo nível, que não conseguiam completar as vagas dos cursos de graduação, mesmo no processo seletivo mais aligeirado que a legislação 
permite, as que demonstraram preferência por esse tipo de curso. Os alunos que não conseguiam ingressar nos cursos de graduação eram chamados aos seqüenciais, com o objetivo de acumular créditos que poderiam ser aceitos, posteriormente, pelos cursos de graduação. Ou, então, para ocuparem as vagas não preenchidas nos cursos de graduação ou deixadas livres pelos evadidos deles. Uma forma, portanto, de reduzir a capacidade ociosa ou, dito de outra forma, de elevar a receita com relação aos custos fixos.

Mas os efeitos da LDB no ensino superior fizeram-se sentir em seus silêncios tanto quanto em suas determinações explícitas. É o caso do modo de seleção dos estudantes para os cursos de graduação.

Desde 1911 os candidatos a todos os cursos de graduação deveriam submeter-se a processos seletivos denominados exames (ou concursos) vestibulares. No início, os candidatos deveriam ser aprovados nos exames; desde os anos de 1970, bastava obter nota diferente de zero, desde que a classificação os situasse no número prefixado de vagas. Mas os exames (ou concursos) eram obrigatórios. Sua razão explícita era selecionar os candidatos intelectualmente habilitados aos cursos superiores, já que não havia um processo institucionalizado de fazê-lo no próprio ensino secundário, ao longo dele nem ao seu fim (exame de Estado).

Rompendo com um dos elementos tradicionais do ensino superior brasileiro, a LDB-96 não menciona os exames (concursos) vestibulares, embora faça referência à aprovação em "processos seletivos" e à exigência de conclusão do ensino médio como condições para um candidato ser admitido em qualquer curso de graduação. Essa omissão abriu caminho para que as instituições de ensino superior adotassem diversos processos de admissão de estudantes, conforme sua inserção mais ou menos colada ao mercado do ensino superior. Mais adiante será feita referência a alguns desses processos.

\section{Normatização fragmentada}

Durante a tramitação da LDB pelo Congresso Nacional, quando ainda competiam dois projetos, um da Câmara dos Deputados, outro do Senado, o governo federal enviou ao Poder Legislativo projetos de lei visando à normatização de aspectos importantes do ensino superior, que seriam objeto daquela lei inclusiva. Ao invés de aguardarem a promulgação da LDB, eles foram sendo aprovados, com ou sem alguma modificação. Além disso, decretos presidenciais ajudaram a moldar o 
que chegou a ser chamado de uma nova reforma universitária realizada "no varejo".

Nos itens abaixo vamos abordar os elementos mais importantes dessa normatização fragmentada, a que foi feita antes, ao lado e até mesmo depois da LDB.

\section{Acesso aos cursos de graduação}

As primeiras declarações do ministro da Educação, logo depois de sua posse e ainda antes que a LDB fosse aprovada pelo Congresso, foram no sentido de mudar radicalmente o padrão de seleção de candidatos ao ensino superior, ou seja, modificar a via única dos exames vestibulares, em vigor desde 1911.

As críticas que esse mecanismo vinha sofrendo, por não propiciar uma seleção adequada dos candidatos, levou o ministro a apoiar a proposta, já acolhida por seu antecessor, de substituí-lo por avaliações semestrais ao longo do ensino médio.

Algumas instituiçôes, como a Universidade de Brasília, já vinham fazendo exames desse tipo há alguns anos, com alunos da rede pública do Distrito Federal, que disputaram metade das vagas oferecidas. Em 1998, essa universidade veio a ter o primeiro contingente de calouros ingressantes por essa via, sem, contudo, abolir os exames vestibulares. Estes foram feitos pelos alunos não beneficiados pela nova modalidade, isto é, pelos egressos das escolas privadas e pelos oriundos de outras unidades da Federação, que disputaram a outra metade das vagas.

Mas o que ocorreu foi a implantação de um mecanismo diferente desse. O MEc instituiu um Exame Nacional do Ensino Médio (ENEM), uma espécie de exame de Estado, facultativo, mas que poderia vir a ser obrigatório.

Os alunos da terceira série do ensino médio poderiam se inscrever nesse exame, realizado no mesmo dia em todo o país, nas capitais dos estados e nas principais cidades do interior. O conteúdo do exame era o do ensino médio, em provas elaboradas de modo que se favorecessem a interdisciplinaridade e a aplicação prática, sem privilégio da memorização. ${ }^{7}$ Um imenso aparato foi elaborado por entidades privadas sem fins lucrativos, as mesmas que vieram a se responsabilizar pelo Provão, de que trataremos mais abaixo.

O resultado do ENEM é entregue só ao aluno que o fez. A expectativa do MEC, desde o início, era que os empregadores pudessem valorizar 
esse resultado como indicador do nível intelectual do jovem e, principalmente, que as instituiçóes de ensino superior o aproveitassem para a seleção dos candidatos. ${ }^{8}$

Desde logo, as instituições privadas incorporaram o resultado do ENEM como parte ou como toda a indicação de desempenho para selecionar os candidatos, mas as instituições públicas resistiram a ele. Com o tempo, e por efeito das pressões do ministério, mesmo as grandes universidades públicas incorporaram o resultado do ENEM para substituir a primeira fase do processo seletivo ou para integrá-la, valendo um certo número relativo de pontos. ${ }^{9}$

$\mathrm{O}$ efeito disso foi que a procura pelo ENEM aumentou, desde sua implantação em 1998, o que induziu um efeito na demanda, que acabou por gerar maior aceitação pelas instituições de ensino superior.

O ENEM torna-se, assim, um exame de saída do ensino médio, mas, ao mesmo tempo, um exame de entrada no ensino superior, guardando semelhanças (a despeito do caráter facultativo) com o baccalauréat francês e o Abitur alemão.

A LDB-96 silenciou-se sobre os exames vestibulares. Obrigatórios para todas os cursos superiores, desde 1911, ela foi a primeira lei que nada disse a respeito. Um silêncio eloqüente, em tudo coincidente com o projeto ministerial de tornar o ENEM o principal mecanismo de seleção. No entanto, houve universidades, mormente no setor público, que mantiveram os exames vestibulares como mecanismo exclusivo de seleção de candidatos, não utilizando os resultados do ENEM até o fim do octênio FHC.

\section{Poder docente na gestão universitária}

Durante as duas décadas da ditadura militar, o processo de cooptação para a escolha dos dirigentes das universidades e faculdades públicas foi alvo de muitas e severas críticas. Contudo, os artifícios encontrados para contornar esse processo não ficaram isentos de rejeição, mesmo no interior das instituições que se beneficiaram deles.

Saudada nos anos de 1980 como o advento da democratização da gestão universitária, a prática de consultas (eleiçôes) para a elaboração das listas de candidatos a reitor deu ensejo a artifícios que limitavam o poder de cooptação da instância superior e/ou sobrevalorizavam o peso dos votos dos estudantes e dos funcionários técnico-administrativos. 
Numa medida marcadamente reativa, foi aprovada a Lei $\mathrm{n}^{\circ}$ 9.192/ 95, a partir de projeto do MEC, que determinou mudança radical na escolha de dirigentes das universidades federais. Ao contrário do que se fazia, normalmente, a proporção de docentes das universidades federais participantes dos órgãos colegiadas máximos passou a ser de no mínimo $70 \%$. Este foi, também, o peso do voto dos docentes no caso de consulta à comunidade universitária sobre os candidatos a reitor e vice-reitor. Independentemente da consulta, os colegiados superiores devem reunir-se em colégio eleitoral para elaborar uma lista tríplice, em votação uninominal, em turno único. Dessa lista, o presidente da República ou o ministro, por delegação sua, escolhe o reitor. Em procedimento análogo é escolhido o diretor de unidade universitária, sendo que, nesse caso, o reitor é que faz a escolha, institucionalizando-se uma delegação provisória. Os candidatos a reitor e a diretor de unidade devem pertencer aos dois níveis mais elevados da carreira docente (titular ou adjunto) ou, então, devem ser portadores do grau acadêmico de doutor. Nas universidades federais, a recondução de reitores e diretores (quatro anos de mandato) passou a ser permitida, mas apenas uma vez para o mesmo cargo.

Os titulares de cargos análogos nas universidades estaduais ou municipais são escolhidos conforme determinações dos respectivos sistemas de ensino. Os das privadas, de acordo com seus estatutos.

$\mathrm{O}$ resultado disso foi, pelo menos nas universidades federais, a manutenção do poder nos níveis mais elevados da categoria docente. No entanto, o poder dos estudantes e dos funcionários técnico-administrativos tem sido forte e eficaz, em decorrência da composição mais homogênea de suas bancadas (em geral, 15\% dos votos para cada uma), propiciada pela sustentação das entidades de caráter sindical, o que não é o caso dos docentes.

Todavia, o conflito permanece, latente ou manifesto, gerado pela reivindicação de voto paritário ou censitário (este pelos estudantes), assim como o fim do processo de cooptação, que ressurge, nesse caso, a cada escolha de nome pouco votado na consulta, pelo titular do Poder Executivo.

Ainda no ano de 1995, outras duas medidas de grande alcance foram tomadas, contidas ambas na Lei $n^{\circ}$ 9.131/95, que tratou, no mesmo documento, do Conselho Nacional de Educação e dos Exames Nacionais de Cursos, que focalizaremos a seguir.

\section{Conselho Nacional de Educação}

Durante duas décadas de ditadura (1964/85), as afinidades políticas dos empresários do ensino com os governos militares abriram 
caminho para mais e mais representantes de escolas, faculdades e universidades privadas nos conselhos de educação. Tornando-se maioria, eles passaram a legislar em causa própria. Os resultados foram expressos em cifras estatísticas e financeiras. Impulsionados pela demanda de vagas, pelo freio na velocidade de expansão das redes públicas de ensino e, especialmente, pelas normas facilitadoras, as instituições privadas de ensino multiplicaram-se em número e cresceram em tamanho. Em qualquer capital de estado e até mesmo nas cidades médias do interior, pequenos ginásios e cursinhos pré-vestibular acumularam capital, alunos pagantes e níveis de ensino. Alguns viraram universidades. Mais recentemente, as instituições privadas de ensino ingressaram no lucrativo serviço de franquias.

O poder do Conselho Federal de Educação, instituído pela primeira LDB (1961), transformou-o num órgão cobiçado pelos empresários do ensino. Como dele dependiam as autorizações, reconhecimento e credenciamento, de cursos e de instituiçóes, os empresários do ensino e seus prepostos, amparados pelas composições políticas da ditadura militar, lograram constituir a maioria, quando não a totalidade desse Conselho. As denúncias de corrupção atingiram o auge no governo interino de Itamar Franco, que dissolveu o Conselho e enviou ao Congresso projeto de lei que criou outro órgão colegiado no seu lugar. ${ }^{10}$

A Lei no 9.131/95 criou, então, o Conselho Nacional de Educação, com funções homologatórias no que diz respeito às políticas gerais do ministério, mas tendo a última palavra no que se refere ao reconhecimento de cursos, à criação de instituições de ensino superior e ao credenciamento de universidades, assim como é sua responsabilidade a última etapa do processo de avaliação das universidades visando ao recredenciamento periódico.

Dentre as atribuições do CNE, destacam-se as seguintes: (i) analisar e emitir parecer sobre os resultados dos processos de avaliação da educação superior; (ii) deliberar sobre os relatórios para reconhecimento periódico de cursos de mestrado e doutorado, elaborados pelo MEC, com base na avaliação dos cursos. As seguintes três atribuições o conselho poderá exercer diretamente ou delegá-las aos seus homólogos estaduais: (i) deliberar sobre os relatórios encaminhados pelo MEC sobre o reconhecimento de cursos e habilitações oferecidos por instituições de ensino superior, assim como sobre a autorização prévia daqueles oferecidos por instituições não-universitárias; (ii) deliberar sobre a autorização, o credenciamento e o recredenciamento periódico de instituições de educação superior, inclusive de universidades, com base em relatórios e avaliações apresentados pelo MEC; (iii) deliberar sobre os estatutos das 
universidades e o regimento das demais IES que fazem parte do sistema federal.

Se comparadas com as de seu antecessor, as atribuições do CNE ficam dependentes de relatórios e avaliações realizados pelos órgãos técnicos do MEC, o que, para uns, pode resultar em decisões limitadas pelos termos propostos; para outros, em proteção ao próprio Conselho, impedindo que seu quadro técnico volte a ser mera agência de intermediaçãao das instituiçõos interessadas, especialmente das privadas, com o Poder Público.

Até a metade dos 24 membros do CNE é escolhida livremente pelo presidente da República, incluindo os dois membros natos, os secretários de Ensino Fundamental e do Ensino Superior. Pelo menos metade dos membros é escolhida pelo presidente em listas apresentadas por entidades da sociedade civil, relacionada às áreas de atuação da Câmara de Educação Básica e da Câmara de Educação Superior. $\mathrm{Na}$ primeira composição do $\mathrm{CNE}$, isto é, a do início de 1996, seus membros foram indicados em dois turnos por entidades de finalidade científica, cultural e sindical. A análise da primeira fornada de conselheiros, nomeados todos entre os indicados pelas entidades consultadas, mostra que eram em número significativo (ainda que não majoritário) os que se orientavam pela defesa do ensino público, algo inédito nessa instância do Estado, na qual prevaleceu a intermediação de recursos do governo para as instituições privadas e a legislação em causa própria.

Mas esse mecanismo de captação de indicações, que poderia vir a ser uma via de aperfeiçoamento na formulação de políticas e na administração dos sistemas de ensino, mostrou-se permeável ao privatismo, como no antigo CFE, no qual só a preferência do presidente valia. A Câmara de Educação Superior do CNE, na qual se debatem hoje os grandes interesses privados, acabou virando arena de disputa entre os próprios grupos privados, na luta pelo controle do mercado.

A guinada privatista na Câmara de Educação Superior do CNE tem uma explicação: a necessidade de manter uma base parlamentar garantidora dos votos capazes de aprovar os projetos do governo levou o presidente a trocar votos no Congresso por nomeaçóes para postos no Poder Executivo, inclusive no $\mathrm{CNE}$ - e foram os grupos privatistas que se beneficiaram nessa barganha.

Ao termo do longo Governo FHC, a Câmara de Educação Superior do CNE tornou-se tão desmoralizada quanto todo o CFE ao fim do curto mandato de Itamar Franco. Sintomaticamente, seus membros até mesmo 
se recusaram à audiência pública da Comissão de Educação da Câmara dos Deputados, que investiga denúncias de irregularidades e tráfico de influência no CNE.

\section{Avaliação}

Contrariando a proposta de governo do candidato Fernando Henrique Cardoso, o foco da avaliação do ensino superior deslocou-se da dimensão institucional para a dimensão individual. Ao passo que o Programa de Avaliação Institucional das Universidades Brasileiras (PAIUB) era sensivelmente desacelerado, e a Lei no 9.131/95 dizia que o MEC procederia a "avaliações periódicas das instituições e dos cursos de ensino superior, fazendo uso de procedimentos e critérios abrangentes, dos diversos fatores que determinam a qualidade e a eficiência das atividades de ensino, pesquisa e extensão", o que se instituiu mesmo foram os Exames Nacionais de Cursos, ${ }^{11}$ os quais seriam obrigatórios para todos os estudantes do último ano dos cursos superiores de graduação do país. Os resultados relativos a cada instituição de ensino deveriam ser empregados, não exclusivamente, na avaliação de cada curso e de cada instituição de ensino superior.

Os exames são facultativos para os alunos, mas prestá-los passou a ser condição para a obtenção do diploma. No histórico escolar de cada concluinte consta apenas o registro da data em que ele se submeteu ao exame, não o resultado obtido. Este é fornecido apenas ao aluno, sendo vedada a divulgação dos resultados individualizados. Caso o resultado do exame não convenha ao aluno, ele pode submeter-se aos exames nos anos subseqüentes, fazendo jus a novo documento. Todavia, para efeito da avaliação do curso, é considerado somente o resultado do exame prestado pelo aluno no ano da conclusão.

Os exames foram previstos para serem implantados gradativamente. Em 1996, foram submetidos aos exames de conclusão de curso os estudantes inscritos nas disciplinas do último período dos cursos de Direito, Administração e Engenharia Civil. A cada ano, quatro novos cursos foram incluídos no processo, na expectativa de que todos venham a ser objeto do Exame Nacional de Cursos.

Para a definição dos objetivos e outras especificações necessárias à elaboração das provas, o ministro da Educação constitui uma comissão para cada curso, composta de até dez pessoas, mediante cooptação, de modo que esteja garantida a representação do Conselho 
de Reitores das Universidades Brasileiras, dos conselhos federais e das associações nacionais de ensino das profissões regulamentadas. Com base nas especificações dessas comissões, as provas são elaboradas e aplicadas por entidades sem fins lucrativos, externas ao MEC e às instituições a serem avaliadas, "que tenham em seus quadros profissionais que atendam a requisitos de idoneidade e capacidade técnica em avaliação da aprendizagem, elaboração e aplicação de provas e testes".

Em novembro de 1996, 55 mil estudantes de 616 instituições foram chamados ao Provão, mas, pelos cálculos do MEC, 4\% entregaram a prova em branco, apoiando, assim, o boicote defendido pela União Nacional dos Estudantes (UNE). ${ }^{12}$ Como se computou nota zero para os alunos que entregaram a prova em branco, o resultado da avaliação, divulgado em abril de 1997, mostrou cursos de excelência com nota média inferior à de outros de duvidosa qualidade. Diante das críticas que o processo recebeu nos meios de comunicação de massa, o ministro anunciou que as faculdades posicionadas na faixa de notas mais baixas seriam visitadas por comissões de especialistas (estes, então, é que disporiam de critério decisivo) para recomendarem ou não seu descredenciamento ao Conselho Nacional de Educação.

Quase dois anos depois que a lei instituidora do Exame Nacional de Cursos havia sido promulgada, depois que ele havia sido simbolicamente rejeitado pelos estudantes mediante o apodo de Provão, depois de acionado o processo de aplicação dos primeiros testes, foi que o Ministério da Educação resolveu montar um dispositivo legal inclusivo de avaliação. Não havia mais como defender o Provão apenas com os argumentos utilizados até então. Com efeito, como responder às críticas de que a dimensão institucional das IEs estava sendo deixada de lado em proveito da dimensão individual? Como dar credibilidade à afirmação de que o PAIUB estava em plena vigência?

O Decreto no 2.026, de outubro de $1996,{ }^{13}$ pretendeu, então, apoiar os argumentos ministeriais, mediante previsão de procedimentos para o processo de avaliação dos cursos e das instituições de ensino superior. Ele compreenderia os seguintes procedimentos: (i) análise dos principais indicadores de desempenho global do sistema nacional de ensino superior, por região e unidades da Federação, segundo as áreas do conhecimento e o tipo ou a natureza das instituiçôes de ensino; (ii) avaliação do desempenho individual das instituiçôes de ensino superior, compreendendo todas as modalidades de ensino, pesquisa e extensão; (iii) avaliação do ensino de graduação, por curso, por meio da análise das condições de oferta pelas diferentes instituiçôes de ensino e pela 
análise dos resultados do Exame Nacional de Cursos; e (iv) avaliação dos programas de mestrado e doutorado, por área do conhecimento.

Tais procedimentos são complementares, porém independentes. Eles podem ser conduzidos em momentos diferentes e fazer uso de distintos métodos e técnicas. Com esse dispositivo, garante-se a continuidade do Provão, a que fica adicionado um trabalho de levantamento e apuração de dados pela Secretaria de Avaliação e Informação Educacional, do MEC, para o cálculo dos indicadores de desempenho global.

A avaliação de cada IES deve ser conduzida por uma comissão externa à instituição, especialmente designada pela Secretaria de Educação Superior, do Ministério da Educação. A comissão deve considerar, entre outros, os seguintes aspectos: eficiência das atividadesmeio em relação aos objetivos da instituição; adequação dos currículos dos cursos de graduação; inserção da instituição na comunidade local e regional; produção científica, cultural e tecnológica. Ademais, a comissão deve levar em conta a auto-avaliação da instituição, a avaliação dos cursos desenvolvida pelas comissóes de especialistas, os resultados dos exames nacionais dos cursos de graduação e a avaliação da pós-graduação. Esta última continua a ser desenvolvida pela Coordenação de Aperfeiçoamento de Pessoal de Nível Superior (CAPES), conforme os métodos vigentes desde meados da década de 1970, em especial o julgamento pelos pares, que utilizam as informaçōes fornecidas pelos próprios programas de pós-graduação.

Além da avaliação institucional, da pressuposta auto-avaliação de cada IES e do Exame Nacional de Cursos, o decreto prevê, também, a avaliação das condiçôes da oferta dos cursos de graduação, que deverá considerar os seguintes fatores: (i) a organização didático-pedagógica; (ii) a adequação das instalaçôes físicas em geral; (iii) a adequação das instalaçôes especiais, tais como laboratórios, oficinas e outros ambientes indispensáveis à execução do currículo; (iv) a qualificação do corpo docente; e (v) as bibliotecas.

Considerando o que determina a Lei $\mathrm{n}^{\circ} 9.131 / 95$, esse complexo processo culmina no Conselho Nacional de Educação, a cuja Câmara de Educação Superior compete analisar e emitir parecer sobre os resultados dos processos de avaliação.

Ao fim do octênio FHC, 12 cursos de graduação de matemática e de letras receberam sançôes negativas (foram proibidos de admitir novos estudantes), mesmo assim só após cinco resultados deficientes 
consecutivos, confirmados por inadequadas condições de oferta, verificadas no local. No entanto, a sanção foi suspensa por medida judicial, enquanto tramita ação que contraria os critérios empregados pelo ministério. Apenas uma IES (privada, situada na periferia da área metropolitana do Rio de Janeiro) perdeu o status universitário da autonomia, por idêntica razão, em escala ampliada.

Os efeitos reduzidos de um tão grande aparato só podem ser compreendidos se referidos ao processo de ampliação da representação privatista na Câmara de Educação Superior do Conselho Nacional de Educação, explicável, como já foi dito mais acima, pelo mecanismo de permuta política no âmbito do Congresso Nacional.

Em suma, a principal oposição ao Provão proveio do setor privado, que preferiu não expor o baixo desempenho dos seus estudantes, comparativamente com os do setor público. Por distintas razóes, os estudantes das instituições públicas de ensino superior igualmente a rejeitam. Para eles, a avaliação individual tem sido considerada um procedimento intrinsecamente condenável. Os empresários do ensino têm sido vitoriosos, pois conseguiram que os resultados de cada instituição não fossem divulgados. Já a UNE tem sido derrotada pelos próprios estudantes, porque foi de apenas $4 \%$ o número de concluintes que boicotaram o Provão, em 1996, proporção esta que tem diminuído a cada ano.

\section{Formato institucional}

A universidade tem sido a instituição idealizada para o ensino superior brasileiro desde a promulgação do primeiro documento legal que lhe faz referência (o Estatuto de 1931) por mais que ela tenha sido entendida, na prática, como mera aglomeração de escolas, faculdades ou institutos. As faculdades isoladas, embora majoritárias, foram postas em segundo plano, uma espécie de instituição de segunda classe, destinada a desaparecer um dia, quando o espaço do ensino superior fosse plenamente ocupado pela instituição que lhe seria própria - a universidade. Esta, por sua vez, deveria possuir, entre outras, uma característica essencial, a universalidade de campo, mesmo que entendida apenas como a justaposição de uma escola de Engenharia, uma faculdade de Direito e uma faculdade de Medicina, podendo uma delas ser substituída pela faculdade de Filosofia, Ciências e Letras. O desenvolvimento da pós-graduação e da pesquisa nas universidades federais e nas estaduais paulistas, nos anos de 1970, 
levou a que a investigação científica e tecnológica fosse considerada uma característica co-essencial da instituição universitária.

Desde o relatório da Comissão Nacional para a Reformulação da Educação Superior (1986), a universalidade de campo tem sido criticada, no âmbito governamental, em proveito da concepção da universidade especializada por campo do saber, seja pelo reconhecimento do status plenamente universitário para esse tipo de instituição, seja pela atribuição, a ela, apenas(!) do privilégio da autonomia.

Antes que qualquer documento legal amparasse tal redefinição, o presidente Itamar Franco baixou decreto, nos últimos dias de seu governo (dezembro de 1994), transformando a Faculdade Paulista de Medicina em Universidade Federal de São Paulo, sem qualquer contestação de qualquer instituição universitária. $\mathrm{O}$ CFE, já extinto, não poderia opinar. Tal amparo surgiu a posteriori, na LDB-96, que não só previu a possibilidade da universidade especializada por campo do saber como, também, a possibilidade da atribuição da autonomia a "instituições que comprovem alta qualificação para o ensino ou para a pesquisa, com base em avaliação realizada pelo Poder Público".

Com base na LDB-96, o Decreto no 2.306/97 atribuiu um formato peculiar ao sistema de ensino superior, ao projetar importantes modificações no quadro até então existente no que diz respeito à fronteira entre a esfera pública e a esfera privada.

$\mathrm{O}$ decreto determinou que as IES privadas publicassem os demonstrativos do movimento financeiro; empregassem pelo menos $60 \%$ da receita (apenas das mensalidades escolares) ao pagamento de professores e funcionários, incluindo-se, nesse cômputo, os descontos, as bolsas de estudo que oferecessem e os encargos e benefícios sociais dos hospitais de ensino.

As IES privadas que não preenchessem essas condições passariam a pagar impostos e contribuições, como qualquer sociedade mercantil, além de não poderem remunerar seus sócios. Ademais, passaram a ter de se submeter, a qualquer tempo, à auditoria pelo Poder Público, devendo ainda publicar, anualmente, demonstrações financeiras certificadas por auditores independentes.

A organização acadêmica das IES foi também objeto do Decreto $\mathrm{n}^{\circ}$ 2.306/97. As IES podem, agora, adotar cinco formatos diferentes: universidades; centros universitários; faculdades integradas; faculdades; institutos superiores ou escolas superiores. Não se distinguem faculdades e institutos superiores nem escolas superiores, termos que, no Brasil, têm sido utilizados como sinônimos. 
A grande novidade foi o aparecimento dos centros universitários, definidos como instituições de ensino pluricurriculares, que abrangem uma ou mais áreas do conhecimento, "que se caracterizam pela excelência do ensino oferecido, comprovada pela qualificação do seu corpo docente e pelas condiçôes de trabalho acadêmico". Os centros universitários podem receber o privilégio da autonomia para criar, organizar e extinguir, em sua sede, cursos e programas de educação superior, além de outras atribuições definidas em seu credenciamento pelo Conselho Nacional de Educação. ${ }^{14}$

Quase autônomos ou detentores de quase toda a autonomia universitária, os centros universitários ocupam o lugar, no discurso reformista oficial, da universidade de ensino, definida por oposição à universidade de pesquisa, esta sim, a universidade plenamente constituída.

\section{Instituições e estudantes}

O quadro abaixo apresenta os dados estatísticos mais importantes do ensino superior brasileiro, relativos às instituiçóes e ao alunado de graduação.

Número de instituições e de estudantes no ensino superior (graduação), segundo tipo e dependência administrativa - Brasil, 2001.

\begin{tabular}{|l|rcc|}
\hline \multicolumn{1}{|c|}{$\begin{array}{c}\text { INSTITUIÇŌES/ } \\
\text { ESTUDANTES }\end{array}$} & TOTAL & $\begin{array}{c}\text { INSTITUIÇŌES } \\
\text { PÚBLICAS }\end{array}$ & $\begin{array}{c}\text { INSTITUIÇŌES } \\
\text { PRIVADAS }\end{array}$ \\
\hline \multicolumn{1}{|c|}{ Instituiçóes } & & & \\
Universidades & 156 & 71 & 85 \\
Centros Universitários & 66 & 2 & 64 \\
Federaçōes & 99 & 2 & 97 \\
Faculdades Isoladas & 1.036 & 82 & 954 \\
Centr. Educ. Tecnol. & 34 & 26 & 8 \\
\hline \multicolumn{1}{|c|}{ TOTAL } & 1.391 & 183 & 1.208 \\
\hline Estudantes (mil) & & & $1.139,6$ \\
Universidades & $1.956,5$ & 816,9 & 332,5 \\
Centros Universitários & 338,3 & 5,8 & 161,1 \\
Federaçōes & 166,2 & 5,1 & 457,7 \\
Faculdades Isoladas & 538,3 & 80,6 & 0,7 \\
Centr. Educ. Tecnol. & 31,5 & 30,8 & $2.091,6$ \\
\hline \multicolumn{1}{c|}{ TOTAL } & $3.030,8$ & 939,2 & \\
\hline
\end{tabular}

Fontes: MEC/INEP, Censo Escolar, Ensino Superior, 2001. 
Vemos aí que as faculdades isoladas ( $92 \%$ delas privadas) são a maioria das instituições, mas perdem a posição majoritária no alunado para as universidades, que abrangem $64,5 \%$ dos estudantes. Os centros universitários (a maior parte deles oriunda de federaçôes de faculdades) recebem cerca de um décimo das matrículas, quase todas no setor privado. Já os centros de educação tecnológica se situam praticamente todos no setor público e representam uma parcela diminuta na oferta de ensino superior.

Das 156 universidades, a maioria é privada $(85 \times 71)$. Foi muito rápido o crescimento das universidades privadas: no primeiro ano do octênio, elas eram 63. As universidades públicas ficaram estacionadas no mesmo período. Mas o dinamismo do setor privado expressou-se, igualmente, na categoria centros universitários, que não existiam em 1995 e já eram 66 em 2001, dos quais apenas dois públicos.

As universidades públicas não constituem um segmento homogêneo. São 39 as universidades federais, dotadas todas de idêntica carreira docente. As universidades mantidas pelo estado de São Paulo têm carreiras docentes bem distintas daquelas das federais, caracterizando-se pela mais forte hierarquização.

As universidades privadas são também bastante desiguais, comportando algumas instituições de alto padrão acadêmico. Dentre as privadas, destacam-se, por sua ação política coordenada, as instituições confessionais, notadamente as 24 católicas e as 6 protestantes - também elas muito heterogêneas.

Outra importante característica do ensino superior brasileiro é a gratuidade dos cursos de graduação e pós-graduação nas instituições públicas. Embora a gratuidade existisse de fato desde os anos 50, ela só passou a ser garantida de direito pela Constituição de $1988 .{ }^{15}$ Para o setor privado, o governo federal oferece o Programa de Crédito Educativo, que propicia aos beneficiados reembolsarem o valor das anuidades num prazo $50 \%$ maior que o do financiamento, com um ano de carência.

O número de alunos de todos os cursos de graduação ultrapassou um pouco os 3 milhões, $67 \%$ superior aos praticamente 1,8 milhão de 1995. O contigente atual de alunos divide-se entre as instituiçôes públicas e privadas à razão de $31 \%$ para $69 \%$, respectivamente. Em 1995, essa razão era de $39 \%$ para $61 \%$, respectivamente, o que mostra o aumento do tamanho relativo do setor privado, no que concerne ao alunado.

Durante o período analisado, o número de alunos matriculados nos cursos noturnos das instituições privadas praticamente dobrou. Em 
2001 , cerca de $67 \%$ dos estudantes do setor privado estudavam à noite, proporção que caía para $36 \%$ no setor público.

Em 2001, a maioria dos estudantes (56\%) era do sexo feminino, freqüentava cursos noturnos $(57 \%)$ e estava matriculada em instituições sediadas fora das capitais $(53 \%){ }^{16}$

O grande crescimento das universidades privadas desde 1985, especialmente desde 1995, fez com que se invertessem os termos da inequação tradicional do ensino brasileiro. Com efeito, os estudantes matriculados em universidades sempre foram minoria diante dos seus colegas das faculdades isoladas. Mas a situação foi recentemente revertida, pois, em 2002, cerca de $2 / 3$ do alunado já freqüentavam cursos em universidades, contingente esse majoritariamente situado no setor privado $(58 \%)$.

Apesar da grande demanda não atendida, há vagas não preenchidas, tanto no setor público quanto no privado. Nas instituiçōes públicas, 12 mil vagas permaneceram desocupadas em 2002, por falta de candidatos que preenchessem os requisitos mínimos de admissão, fenômeno concentrado em apenas algumas carreiras. Mas as instituições privadas, que adotam critérios bem mais tolerantes, apresentaram 360 mil vagas não preenchidas, nesse ano. A razão aí é de outra natureza: elas ampliam, artificialmente, o número de vagas solicitadas ao MEC, de modo que se pratique uma espécie de "reserva de mercado futuro".

\section{Um balanço}

Façamos, agora, um balanço das políticas para o ensino superior nos oito anos de Governo FHC.

Antes de tudo, vale destacar as mudanças nos mecanismos de acesso ao ensino superior, que, ao eliminar a obrigatoriedade dos exames vestibulares, pretenderam resolver dois problemas, ao mesmo tempo. Primeiro, estabelecer um padrão de qualidade do ensino médio em rápido crescimento, o que pode influenciar sobre a qualidade da demanda de ensino superior. Segundo, reduzir os custos de seleção dos candidatos aos cursos superiores, especialmente das IES privadas, que se vêem na contingência de realizar vários exames ao longo do ano para preencher as vagas disponíveis, situação essa que tende a ficar mais crítica por causa do acirramento da concorrência intra-setorial.

No que diz respeito à proposta de governo de 1994, relativa ao primeiro mandato do presidente $\mathrm{FHC}$, ficou patente que a conexão entre 
o desenvolvimento científico e tecnológico (no qual a universidade teria papel estratégico), de um lado, e o desenvolvimento econômico, de outro, não foi estabelecida. Este, ao contrário, dependeu da importação de capital financeiro e de tecnologia embutida em equipamentos e em processos licenciados.

A redução das despesas das universidades federais, por outro lado, só foi alcançada mediante a compressão dos salários e dos orçamentos, assim como pela não-reposição dos quadros perdidos. A "efetiva autonomia", que seria base da "revolução administrativa", não foi realizada, embora tivesse sido tentada.

Com efeito, um projeto de emenda constitucional oriundo do MEC, em 1996, pretendeu especificar os termos da autonomia das universidades federais. Elas deixariam de ter uma carreira unificada, poderiam contratar e dispensar pessoal, assim como estabelecer os níveis de remuneração de seus docentes e funcionários técnico-administrativos. $\mathrm{O}$ orçamento das universidades federais seria definido de forma global, sem quaisquer rubricas limitadoras, do qual estariam excluídas as receitas próprias. Um Fundo para Manutenção e Desenvolvimento do Ensino Superior seria criado por lei de iniciativa do Poder Executivo, constituído de recursos vinculados ao ensino.

Antes da apreciação do projeto de emenda constitucional pelo Congresso, a LDB adiantou-se ao determinar mudanças em tudo convergentes com aquela. Contrariando a legislação vigente, a LDB abriu a possibilidade de planos de cargos e salários diferenciados, além de competência para as universidades admitirem e demitirem seu pessoal docente e técnico-administrativo.

Um projeto de lei, também elaborado no âmbito do MEC, de mais fácil tramitação no Congresso que uma emenda constitucional, foi submetido à discussão no campo universitário. Embora contivesse elementos positivos para o funcionamento das universidades federais, a exemplo da redução do pesado mecanismo de controle administrativo e financeiro, a autonomia que se oferecia implicava a previsível busca de recursos no mercado para completar os orçamentos públicos minguantes.

Tanto o projeto de emenda constitucional quanto o projeto de lei baseado na LDB foram prontamente rejeitados pelos docentes e pelos funcionários técnico-administrativos. Sem condições políticas para tramitar no Congresso, ambos foram retirados, de modo que a "revolução administrativa" nas universidades federais foi abandonada pelo governo. 
A privatização do ensino superior, isto sim, foi acelerado no período em análise. Como vimos acima, o número de instituições privadas aumentou consideravelmente, em especial na categoria universidades e na dos centros universitários, o que resultou na ampliação do alunado abrangido pelo setor. Tal crescimento fez-se com a complacência governamental diante da qualidade insuficiente do ensino ministrado nas instituições privadas e até mesmo com o benefício do credenciamento acadêmico e do crédito financeiro.

Se, de um lado, as IEs federais padeceram de recursos para continuarem a operar nos termos que antes faziam, e, de outro, as IES privadas recebiam os benefícios visíveis, como deixar de pensar que o sucateamento do setor público do ensino superior correspondia a um intento deliberado? Sem outra referência empírica, esse foi o pensamento dominante naquelas instituições durante o octonato FHC.

Procurando uma visão de conjunto, podemos concluir que as políticas do Governo FHC voltadas para as esferas pública e privada do ensino superior são distintas, mas compatíveis e convergentes.

O protagonismo de agentes do setor público e do setor privado, eficaz a ponto de se refletir na legislação federal, produziu pelo menos duas mudanças profundas no campo do ensino superior brasileiro: a diferenciação das instituições privadas com fins lucrativos, que ficarão excluídas dos benefícios dos recursos públicos, e a diferenciação das instituições dotadas de autonomia universitária, tanto públicas quanto privadas, a maioria delas tendencialmente "rebaixadas" à nova categoria dos centros universitários, onde o princípio constitucional da indissociação entre ensino, pesquisa e extensão deixa de prevalecer.

No discurso dominante no campo, a linha principal de demarcação interna do ensino superior deixou de passar pela divisa entre o estatal e o privado para delimitar a diferença específica entre a excelência e a mediocridade. $\mathrm{Na}$ prática, a divisa foi redefinida, paulatinamente, no âmbito do Ministério da Educação, em especial no Conselho Nacional de Educação, espaço mais visível dos embates entre os protagonistas das distintas posições no campo do ensino superior.

$\mathrm{Na}$ dimensão estritamente econômica da questão, a orientação impressa pelo Ministério da Educação foi no sentido de que a legislação do campo educacional acabe com o capitalismo patrimonial vigente desde a formação do Estado nacional.

O sentido das normas em processo de implantação foi o de estabelecer um capitalismo concorrencial, no qual o investimento realiza- 
do em instituições de ensino deixe de usufruir de condições acintosamente privilegiadas quando comparadas com as de qualquer outro setor econômico. Vale dizer, procura estabelecer a equalização das condições da concorrência. Assim, uma instituição lucrativa não pode estar isenta de impostos e contribuiçōes que incidem sobre todas as outras. As empresas de ensino superior devem operar em regime de transparência, no que se refere à oferta de sua "mercadoria", informando aos seus consumidores, ao início de cada ano letivo: (i) a qualificação de seu corpo docente, a descrição dos recursos materiais à disposição dos alunos; (ii) o elenco dos cursos reconhecidos e dos que estejam em processo de reconhecimento, assim como o resultado das avaliações realizadas pelo MEC; (iii) o valor dos encargos financeiros a serem assumidos pelos alunos e as normas de reajuste aplicáveis durante o período letivo. As penalidades para as instituições transgressoras são as previstas pelo Código de Defesa do Consumidor, que veda a propaganda enganosa e prevê a possibilidade de intervenção pelo Poder Público.

Em suma, verificou-se uma tentativa de estabelecer a ordem num setor tradicionalmente caótico - o das instituições privadas de ensino superior. No entanto, a impossibilidade de tornar eficazes os resultados da avaliação de cursos e de instituições mostrou que, também aí, o Governo FHC foi derrotado pelos grupos que lhe deram sustentação política em seus dois mandatos presidenciais.

Recebido e aprovado em fevereiro de 2003.

\section{Notas}

1. Esta era uma referência à política que o Conselho Nacional de Desenvolvimento Científico e Tecnológico (CNPq) pretendia desenvolver há anos, no sentido de aumentar os gastos em $\mathrm{C} \& \mathrm{~T}$ com aportes das empresas. Em contrapartida, as instituiçôes de pesquisa dedicar-seiam mais e mais à pesquisa aplicada.

2. Esta seria a segunda LDB. A primeira, de 1961, havia sido modificada por muitas leis, tornando-se, além de obsoleta, inoperante em termos práticos.

3. A partir de agora, a expressão IES será empregada, neste texto, como sinônima de instituição de ensino superior ou seu plural.

4. Como veremos adiante, nessa possibilidade foi assentada a criação por decreto de um novo tipo de instituição de ensino superior, o centro universitário.

5. A exceção fica por conta das universidades estaduais paulistas, que gozam de autonomia financeira parcial, já que dispõem de uma proporção preestabelecida da receita de impostos e da liberdade para definir seu emprego.

6. O próprio senador Darcy Ribeiro, patrono da LDB, que veio a ter seu nome, não deixou a definição concernente. Sua morte, logo depois, veio a complicar o trabalho do CNE.

Educ. Soc., Campinas, vol. 24, n. 82, p. 37-61, abril 2003

Disponível em <http://www.cedes.unicamp.br> 
7. O MEC definiu 5 competências consideradas básicas para todo cidadão, as quais foram traduzidas em 21 habilidades, que servem de orientação para a elaboração das provas.

8. O certificado do ENEM não substitui o certificado do ensino médio, de modo que, sem este, um candidato não pode ingressar num curso superior só com uma nota elevada naquele exame.

9. Em 2002, mais de 400 instituições incluíram os resultados do ENEM em seu processo seletivo.

10. O novo Conselho foi inspirado no projeto de LDB que tramitava na Câmara dos Deputados, que era apoiado pelas instituições (para)sindicais do magistério, em todos os níveis.

11. A rigor, a Lei $\mathrm{n}^{\circ} 9.131 / 95$ não usa essa denominação, que só veio a ser empregada pela portaria MEC no $249 / 96$, a qual estipulou os procedimentos a serem adotados.

12. Esta última porcentagem pode ser maior, já que um certo número de estudantes respondeu ao questionário socioeconômico, mas não às questôes de conteúdo.

13. Baixado no mês anterior ao da aplicação das primeiras provas.

14. Originalmente, os centros universitários foram concebidos para propiciarem a diferenciação das instituições públicas de ensino superior, mormente para a reclassificação das universidades de menor peso acadêmico na pós-graduação e na pesquisa científica e tecnológica.

15. Nas instituições de ensino superior criadas e mantidas pelo estado de São Paulo, o ensino passou a ser gratuito pela Constituição estadual de 1947.

16. Estão nesse caso as cidades do interior dos estados e, principalmente, as das periferias das áreas metropolitanas.

\section{Referências bibliográficas}

CARDOSO, F.H. Mãos à obra Brasil: proposta de governo. Brasília: SDE, 1994.

CUNHA, L.A. Políticas para o ensino superior no Brasil: até onde irá a autonomia universitária? Educação \& Sociedade, Campinas, n. 55, ago. 1996.

CUNHA, L.A. Política para o ensino superior: do GERES à LDB. Sociedade \& Estado, Brasília, v. 12, n. 1, jan./jun. 1997.

CUNHA, L.A. O público e o privado no ensino superior brasileiro: fronteira em movimento? Avaliação, Campinas, v. 2, n. 4, dez. 1997.

CUNHA, L.A. A nova reforma do ensino superior: a lógica reconstruída. In: Trindade, H.; Blanquer, J.-M. (Org.). Os desafios da educação na América Latina. Petrópolis: Vozes, 2002.

CURY, C.R.J. Reforma universitária na nova Lei de Diretrizes e Bases da Educação Nacional. Cadernos de Pesquisa, São Paulo, n. 101, jul. 1997. 
DURHAM, E. O sistema federal de ensino superior: problemas e alternativas. Revista Brasileira de Ciências Sociais, São Paulo, n. 23, out. 1993.

RIBEIRO, M.G.M. Educação superior brasileira: reforma e diversificação institucional. Bragança Paulista: Univ. São Francisco, 2002.

TRINDADE, H. (Org.). A universidade em ruinas na república dos professores. Petrópolis: Vozes, 1999. 